\title{
AGREEMENT NEGOTIATION SUPPORT IN VO CREATION
}

\author{
Ana Inês Oliveira ${ }^{1}$, Luis M. Camarinha-Matos ${ }^{1,2,}$ Michel Pouly $^{3}$ \\ ${ }^{1}$ UNINOVA, PORTUGAL, aio@uninova.pt \\ ${ }^{2}$ New University of Lisbon, PORTUGAL, cam@uninova.pt \\ ${ }^{3}$ MTO Network/Swiss Federal Institute of Technology, SWITZERLAND, \\ Michel.pouly@epfl.ch
}

\begin{abstract}
In order to compete in the global market, companies have to restructure and make use of the infrastructures that allow them to become more agile. The possibility of rapidly form virtual organizations to respond to a business or collaboration opportunity gives companies an expression of agility and survival mechanisms in face of the market turbulence. In this paper it is exemplified the usage of a tool that enables time reducing during the negotiation process of a new virtual organization.
\end{abstract}

\section{INTRODUCTION}

The quotation business process is a challenging task for every industrial company active in the subcontracting sector as the customers have nowadays access to a very large global market:

- The success rate of a quotation (transformation into an order) lays around $10 \%$. In other words, it means that 9 out of 10 quotations are only lost time and money;

- The profit margins are reduced and the price calculations must be very accurate;

- The quotation must be ready in a very short time as the competitors also reacts quickly

The quotation process is even more difficult in the case Collaborative Networked Organizations (CNOs). The main drawback here is the supplementary delays induced by the participation of many partners and the need to negotiate till an agreement is reached. In this way, there are several proposed solutions to shorten these delays; for instance, using a kind of workflow tool would enable to follow up the state and the progress of the bid preparation business process. If these delays are not too critical within a local small $\mathrm{CNO}$ where the members share the same language and business background and could probably solve all problems by using the traditional communication methods like e-mails and phone calls, the situation is completely different for multicultural and geographical widely spread organizations. Consequently, there is a need to improve the effectiveness of the negotiation processes and to dynamically form virtual organizations (VOs). It is also important to develop forms of e-contracting as they can describe the rights and duties of all virtual organization partners (Rocha et al., 2004), as well as penalties to apply to 
those that do not satisfy the agreement. Computer assisted negotiation and econtracting is expected to provide a faster and cheaper solution than standard contracting. Several significant characteristics for the e-contracting process can be found in (Angelov, 2006).

Such procedures for e-contracting and negotiation are also important in relation to the ISO 9000 certification as they can ensure clearly defined and repeatable procedures within the $\mathrm{CNO}$ and not only within the companies members of a CNO.

In this context, this paper describes the usage of a negotiation wizard tool developed in the scope of the ECOLEAD project which allows for time-saving during the negotiation process of a $\mathrm{VO}$ creation.

\section{VO CREATION CONTEXT}

In ECOLEAD, the virtual organization (VO) creation process is considered to happen in the context of a VO breeding environment (VBE) (Luis M. CamarinhaMatos \& Afsarmanesh, 2003; Luis M. Camarinha-Matos et al., 2005; Rabelo et al., 2000). The VBE is a long term collaborative association that is composed of organizations that prepared themselves in order to be ready to collaborate and thus rapidly respond to a collaboration opportunity (Luis M. Camarinha-Matos \& Oliveira, 2006; L. M. Camarinha-Matos et al., 2007). As illustrated in Figure 1, the VO creation process is started by a business opportunity identified during the operation phase of the VBE. Although, the VBE is created as a long term "controlled border" association where its members are recruited from the "open universe" of organizations, the VO is supposed to be a short term organization where its partners are primarily selected from the VBE members. Nevertheless in case there is lack of skills or capacity inside the VBE other organizations can be recruited from outside the VBE boundaries (L. M. Camarinha-Matos et al., 2007).

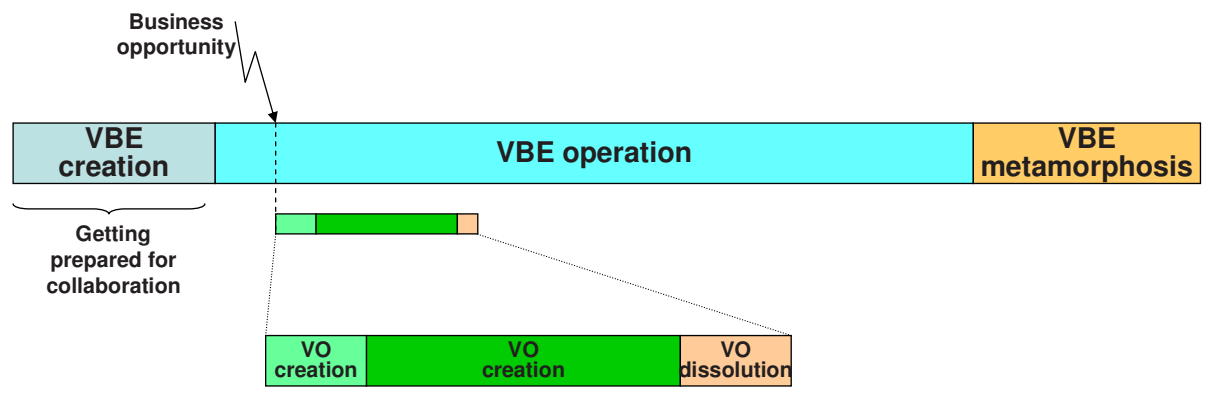

Figure 1 - VO creation in a VBE context

In order to promptly respond to a business / collaboration opportunity, the VO creation process has to be well defined. However, given different market situations, this process has to be set to provide solutions for two distinct cases: (i) when there is already an acquired business opportunity and the objective is to guarantee a consortium to fulfill the opportunity requirements; (ii) before having acquired the business opportunity, it is necessary to go through a quotation process.

Figure 2 shows the simplified process for the VO creation that is supposed to 
happen when there is already an acquired business / collaboration opportunity. In this case, the process can be split into three distinct phases:

- Preparatory Planning. In this phase the new collaboration opportunity (CO) is identified and characterized. Usually the $\mathrm{CO}$ is external (originated by an external client) and identified by a VBE member acting as a broker. After the $\mathrm{CO}$ is identified, it is then characterized and the VO roughly planned determining the rough structure of the potential VO, identifying the required competences and capacities as well as the organizational form and corresponding roles of the consortium members.

- Consortium Formation. This is the main phase of the VO creation. It is when the right partners are identified, assessed and selected according to the characterization and rough planning of the previous phase. In order to compose the $\mathrm{VO}$, in this phase it is also necessary to through an iterative process in order to reach agreements and align needs with offers. This iterative process is conducted by a negotiation process.

- VO Launching. Once partners have been selected and agreements reached, it is necessary to better detail the VO plan according to the previous negotiations, as well as to go through a contracting stage, where all partners become committed to the VO, being the conclusion of the entire negotiation process. Finally, it is necessary to put the VO into operation and for that configuring the needed collaboration infrastructures.

\begin{tabular}{|c|c|c|c|c|}
\hline $\begin{array}{c}\text { CO } \\
\text { Identification }\end{array}$ & & $\begin{array}{r}\text { Partners } \\
\text { search }\end{array}$ & $\mathbf{N}$ & $\begin{array}{l}\text { VT } \\
\text { hing }\end{array}$ \\
\hline $\begin{array}{l}\text {-Who? } \\
\text {-Where and How? } \\
\text {-Which brokerage } \\
\text { policy? } \\
\text {-What is of interest? }\end{array}$ & $\begin{array}{l}\text {-Who? } \\
\text {-Which patterns of } \\
\text { collaboration? } \\
\text {-How to structure } \\
\text { the VO / VT? } \\
\text {-Any initial template } \\
\text { model? }\end{array}$ & $\begin{array}{l}\text {-Who? } \\
\text {-Where? } \\
\text {-Which criteria? } \\
\text {-Which base } \\
\text { information? } \\
\text { Profiles? } \\
\text {-Decision support? }\end{array}$ & $\begin{array}{l}\text {-Who? } \\
\text { •Negotiation } \\
\text { process? } \\
\text { •Contracts, } \\
\text { rules\&templates? } \\
\text {-Agreements? }\end{array}$ & $\begin{array}{l}\text { •Common } \\
\text { infrastructure? } \\
\text { •Governance } \\
\text { principles? } \\
\text { •Detailed plans? }\end{array}$ \\
\hline
\end{tabular}

Figure 2 - VO creation process for a given collaboration opportunity

Nevertheless, before starting planning the VO, it might be necessary to go through a quotation / bidding process of a selected $\mathrm{CO}$. This is the case illustrated in Figure 3 that is divided into two distinct phases:

- Quotation / Bidding. If an interesting CO is identified, then a bid / quotation for the potential customer can be prepared. For the preparation of this bid, it is necessary to make a rough plan of the foreseen $\mathrm{VO}$ and also to select the core partners. In case the bid is unsuccessful, the core consortium dissolves; otherwise the process continues to the next phase.

- Final VO Creation. In case the bid is successful, the VO's rough plan needs to be revised, based on the specific conditions of the contract with the customer, new additional partners might be necessary, and the VO is finally detailed and launched. 


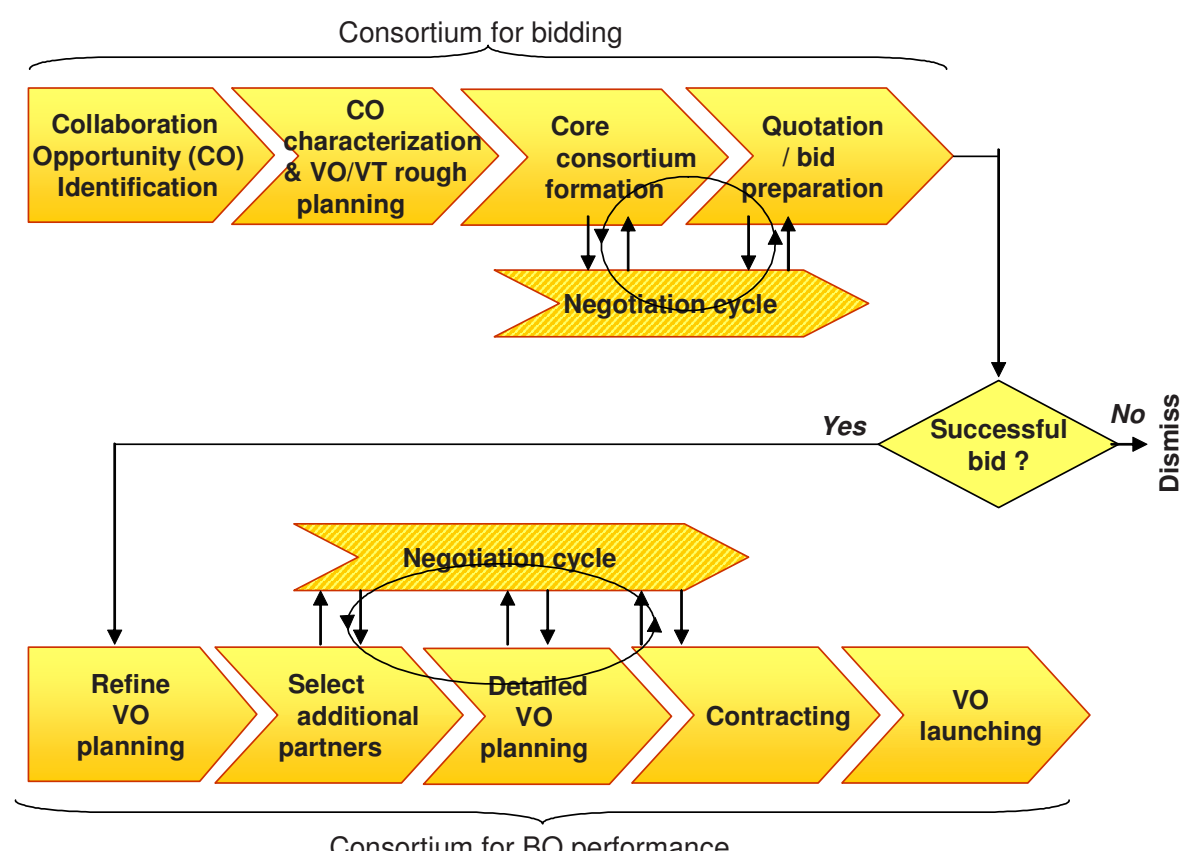

Figure 3 - VO creation process for quotation/bidding

In ECOLEAD, several tools were developed to cover the core phases of the process (L. M. Camarinha-Matos et al., 2007), namely tools for CO identification, characterization and rough planning of the VO, partners search and suggestion, and agreement negotiation wizard.

\section{AGREEMENT NEGOTIATION WIZARD}

In the previous section, the entire process for the VO creation was briefly described. One important process that runs in parallel with some other steps of the VO creation process is the negotiation and contract establishment. Thus, a tool to support this process was developed. The purpose was not to fully automate the process, but rather to assist the human actors during the negotiation process towards the VO establishment. At this point there are two different situations where negotiation might be required: (i) to select the right partners to compose the $\mathrm{VO}$, and (ii) to reach agreements on the details of the VO. The proposed negotiation wizard (WizAN) is intended to provide facilities for both situations.

Usually contracts / agreements are used to regulate the exchange of values (e.g. money, knowledge), and mainly their provisions are for protection of parties in case that something does not go according to what was planned, and to describe what was agreed in the case that any party forgets it. The main result of WizAN is a contract or agreement summarizing the results of the negotiations / discussions that were performed during the $\mathrm{VO}$ creation process. In collaborative business relationships a negotiation might be performed either between two single parties, or among several 
parties (multi-party negotiation). In the case of the contract / agreement produced by the WizAN tool both negotiation types are supported, depending on what is being negotiated (every issue that is subject of negotiation, it is called negotiation topic).

The full negotiation process is guided by a "contract or agreement template" composed of a number of sections. When a negotiation topic is created it is associated to a specific section of the agreement where a link to the topic can be kept (Figure 4). Once all negotiation topics are agreed, the final agreement can be produced representing a kind of "compilation" or integration of the agreements on all these topics.

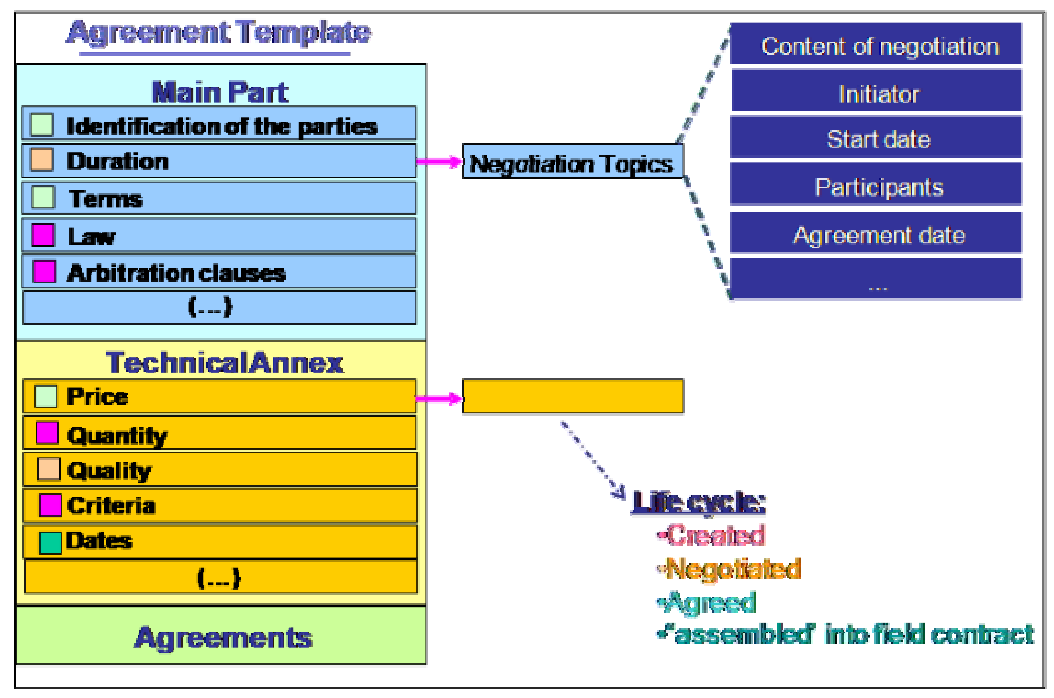

Figure 4 -Agreement template \& Negotiation topics

The negotiation processes is quite hard to structure in terms of defined workflows / protocols as several flows depend of the decisions made by the human negotiators and also their individual timing (mostly asynchronous regarding each other). Thus four main modules were developed to assist the human actors in reaching agreements:

- Assisted Contract Elaboration (ACE). This module provides a collection of contract templates and negotiation topic templates to support the VO creation. In the contract construction process it is possible to build or edit the contract skeleton or template.

- Contract Editor (CE). The contract editor in WizAN is the main point of interaction with the user. Here it is possible for the VO planner to initiate, conduct, and monitor the entire negotiation process in the VO creation. For this, the VO planner has some specific functionality available, such as: add partners to the VO; add, read or edit documents that refer to the general part of the VO; create new virtual negotiation rooms (VNRs); and produce the final document that reflects all the agreements established during the negotiation process. If the user is not the planner and is a potential partner of the $\mathrm{VO}$, there some restrictions in terms of functionalities, but there are also 
other functionalities available, namely: to accept to participate in the VO; see the general conditions that were specified by the VO planner; know who are the other partners involved; read or add documents to the general part of the VO; have access to the VNRs where he/she was invited to participate; and sign the final agreement. Furthermore, it is important to mention that this editor also keeps a list of all the VNRs that were created along with the discussions carried out and documents exchanged. Here privacy and security are both supported since only allowed potential VO partners can access that information.

- Virtual Negotiation Room (VNR). It is the virtual space where the potential partners of the VO are invited to join in order to discuss the necessary topics that need an agreement. When the VO planner wants to discuss a specific topic with certain members, he/she creates a virtual sub-space inside the VO space, i.e. a new virtual negotiation room (Figure 5). Each VNR is divided into two distinct parts: one for edition of the negotiation topic characteristics and associated documents, and another for enabling discussion among partners involved in the negotiation topic by means of chatting (enabling synchronous communication between participants) and/or specific forums that only the members of a that VNR can have access to. The WizAN VNR concept includes therefore several additional functionalities in comparison to other earlier initiatives (Shelbourn et al., 2005).

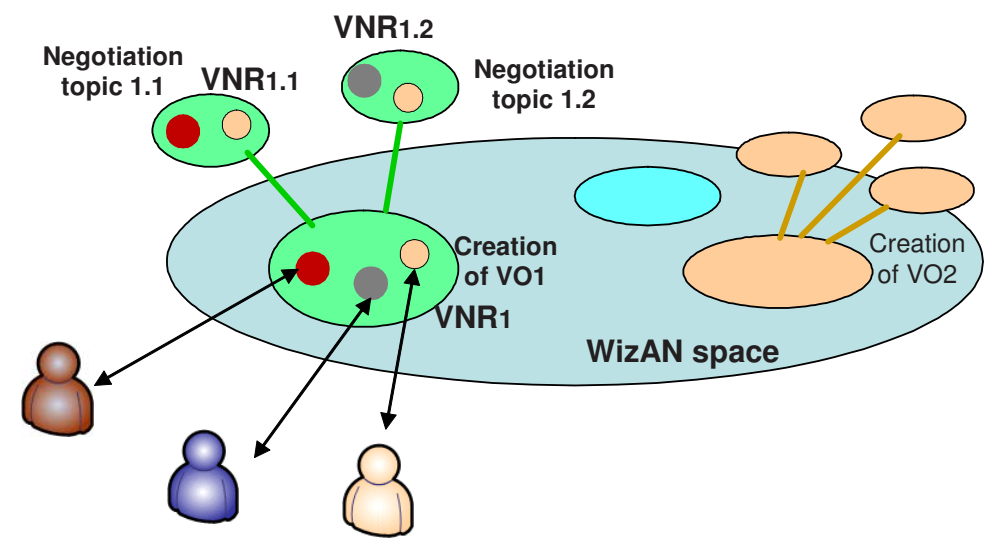

Figure 5 - Virtual spaces (Virtual Negotiation Rooms) in WizAN

- Support for Agreement Establishment (SAE). The e-Notary is a module that allows clients to exchange information with warranty of authenticity and validity as well as providing a safe repository for saving and requesting documentation (through digital signatures and encryption techniques). This module was developed as a web service allowing its clients to use the following facilities: user registry; documents requesting; document signing; document certification; document repository; and document authentication.

In the next section an example of how this tool can be used in a real case scenario is illustrated. 


\section{ILLUSTRATIVE SCENARIO}

The following example scenario is based on the case study of the DecoCHina SwissChinese multicultural CNO. Basically, the DecoCHina CNO consists of two independent networks, the Swiss Microtech regional network (SMT) and a Chinese network located in the Guangdong province, which have their own activities and collaborate on specific orders when it brings a competitive advantage for their customers (Figure 6).

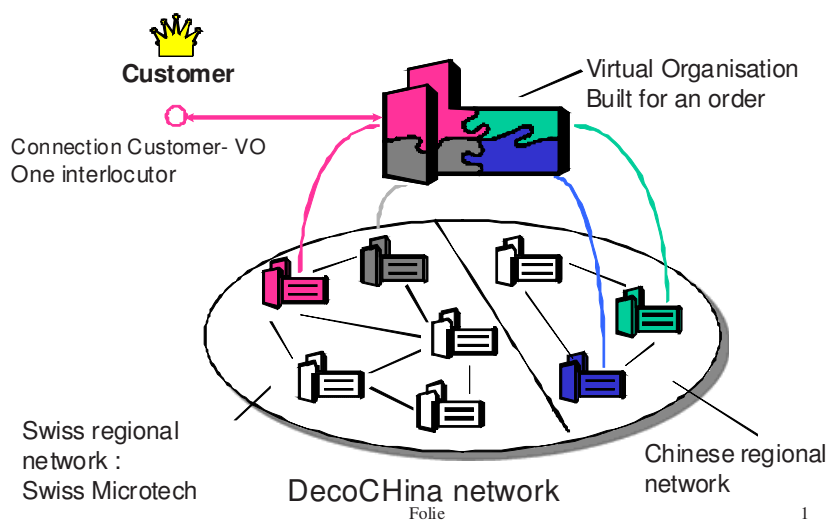

Figure 6 - The DecoCHina CNO

Before starting commercial operations, the following business processes between the two networks have been defined: request for quotation (1), order management (2), and delivery (3).

The request for quotation process will be here analyzed in more details to show where a negotiation support tool is required to reduce the delays which are far too long when only traditional communication methods are used ( 15 working days to get a quotation).

As shown in Figure 7, the first activity of this business process is the request for quotation (2.1) addressed by SMT to the Chinese partner network. This request contains the drawings (dimensions, tolerances, surface quality, and material), the quantities and the corresponding delivery schedules.

The second activity (2.2) is the selection of the potential partners within the Chinese network which could participate in a possible order and which must first give their prices and delivery schedules.

The third activity is the technical clarification (2.3) of the quotation based mainly on the information included in the drawings of the parts and the preparation of a quotation (2.4). The last activity is the commercial negotiation (2.5) on prices and schedules. 

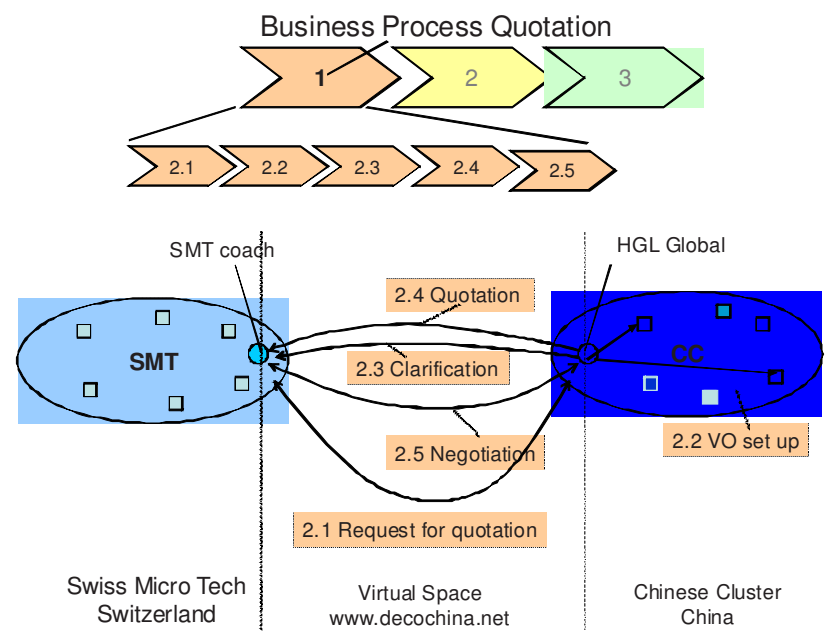

Figure 7 - Interactions of the business process quotation

The agreement negotiation wizard (WizAN) is a tool developed by UNINOVA within the ECOLEAD project and used by the broker or planner in charge of the preparation of a quotation including members of the two networks and allowing him to cover the activities highlighted in $2.2,2.3,2.4$ and 2.5 with the support of the following functionalities:

- Create and edit the main part of a future agreement;

- Add partners for the agreement preparation;

- Create Virtual Negotiation Rooms according to the requested topics to be discussed and agreed upon and invite all or some partners to enter the corresponding room;

- Keep track of the partner's commitments and agreements (e-signatures);

- Produce the final agreement.

The following steps are required to complete the quotation business process:

\section{Step 1}

The SMT broker defines a new possible VO in WizAN (VO characterization Figure 8) with the corresponding documents (drawings in pdf format with dimensions, tolerances, surface quality, material, the quantities and the corresponding delivery schedules) and invites the Chinese network hub company to join the newly created possible common business.

\section{Step 2}

To confirm the reception of the request and in case of interest, the head of the Sales Department accepts the invitation. If not, she must decline it. The SMT broker will call her if no change in the VO partner acceptation status is recorded after max. 1-2 days. 


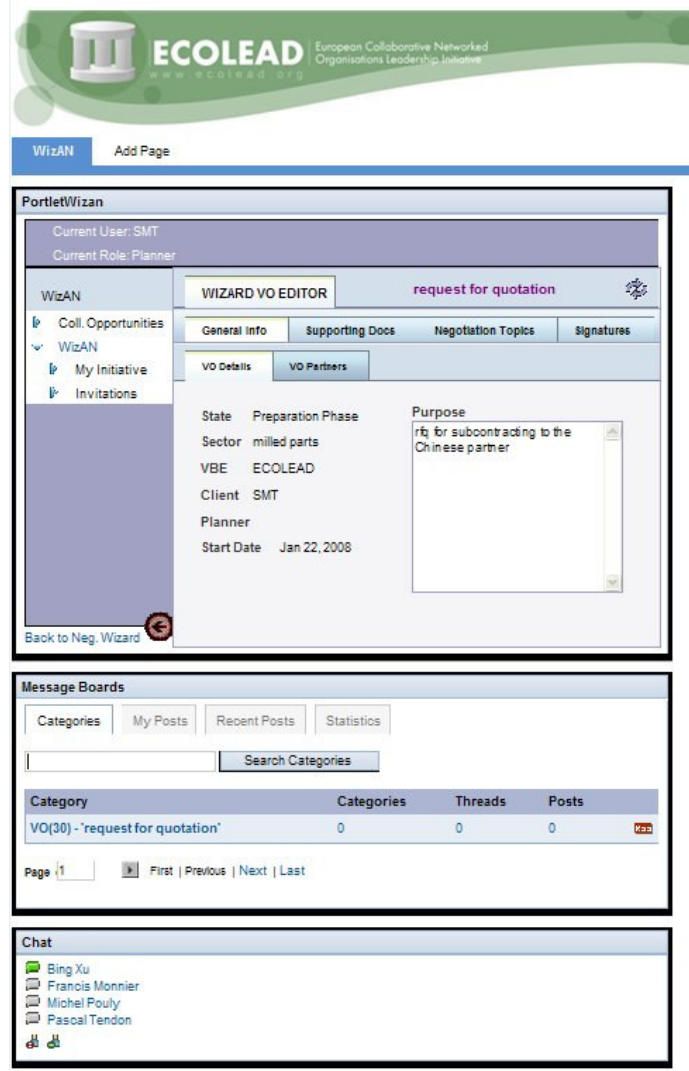

Figure 8 - WizAN user interface for agreement editor - VO characteristics

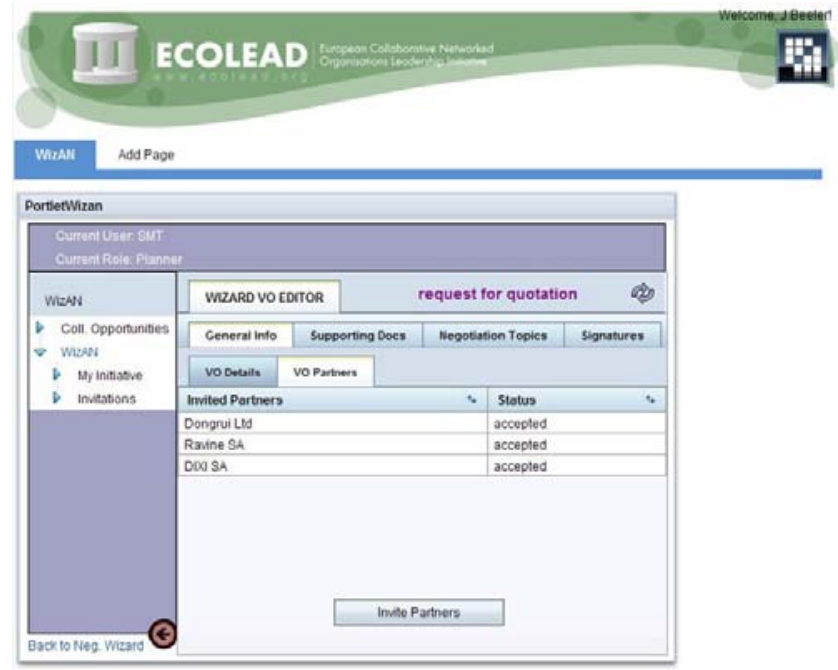

Figure 9 - WizAN user interface for agreement editor - VO invited partners 


\section{$\underline{\text { Step } 3}$}

After the acceptation of all partners (Figure 9), the SMT broker creates three negotiation topics:

1. Technical issues (raw material definition, tolerances, applicable norms etc.);

2. Delivery schedules (example in Figure 10);

3. Price and commercial conditions.

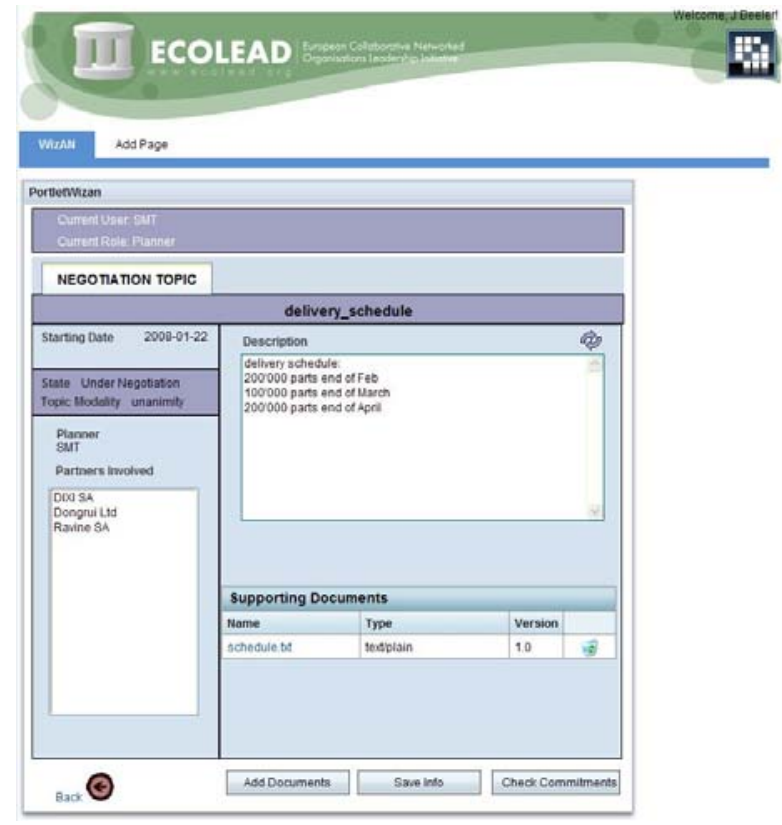

Figure 10 - WizAN user interface for VNR - negotiation topic for delivery schedule

All these topics shall be discussed and agreed by the corresponding partners involved in each topic.

\section{Step 4}

The Sales department of the Chinese hub company forwards the request to its Quotation Engineering department for feasibility analysis and cost calculation together with the collaborators responsible for raw material purchasing and subcontracting. Possible discussions on the negotiation topics will then take place.

For the e-discussions between China and Switzerland during the quotation negotiation phase, users can use the chatting and forums functionality provided by the WizAN tool.

A considerable functionality that can be of great importance is that all documents that are uploaded into the VNRs are stored with versioning control allowing users to keep track of the changes that the documents might have suffered.

After the completion of all technical and commercial negotiation topics, the SMT broker will close the negotiation as illustrated in Figure 11. 


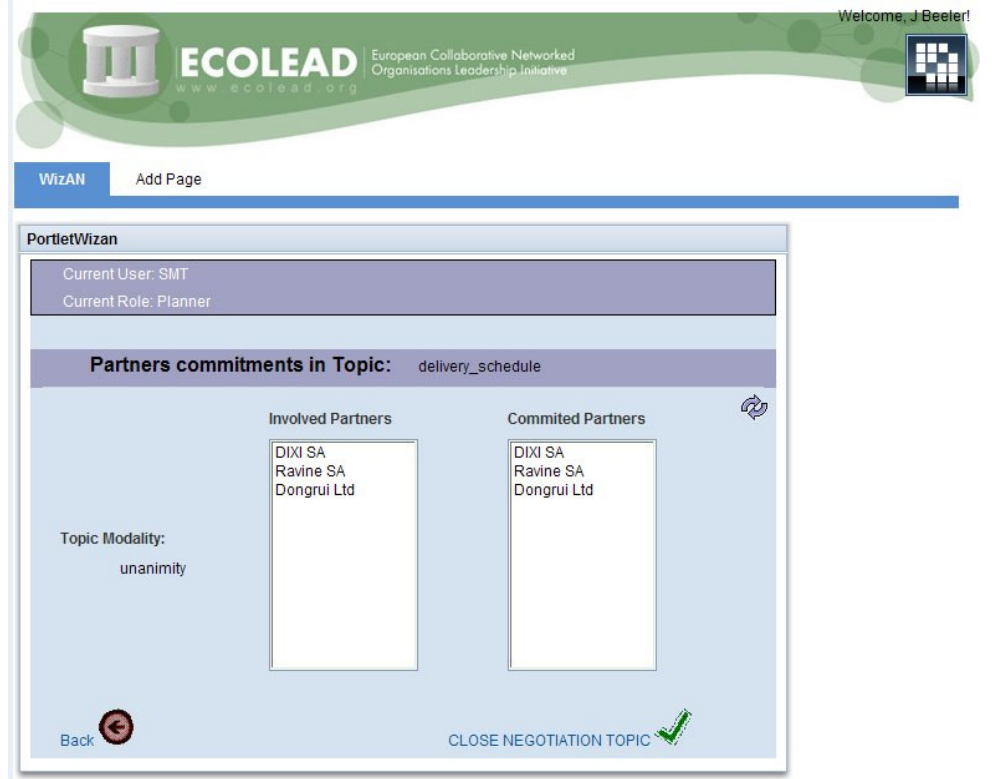

Figure 11 - WizAN user interface for VNR - partners commitment

\section{Step 5}

The SMT broker can create the final agreement, which must be signed by all VO partners before completing the VO creation process.

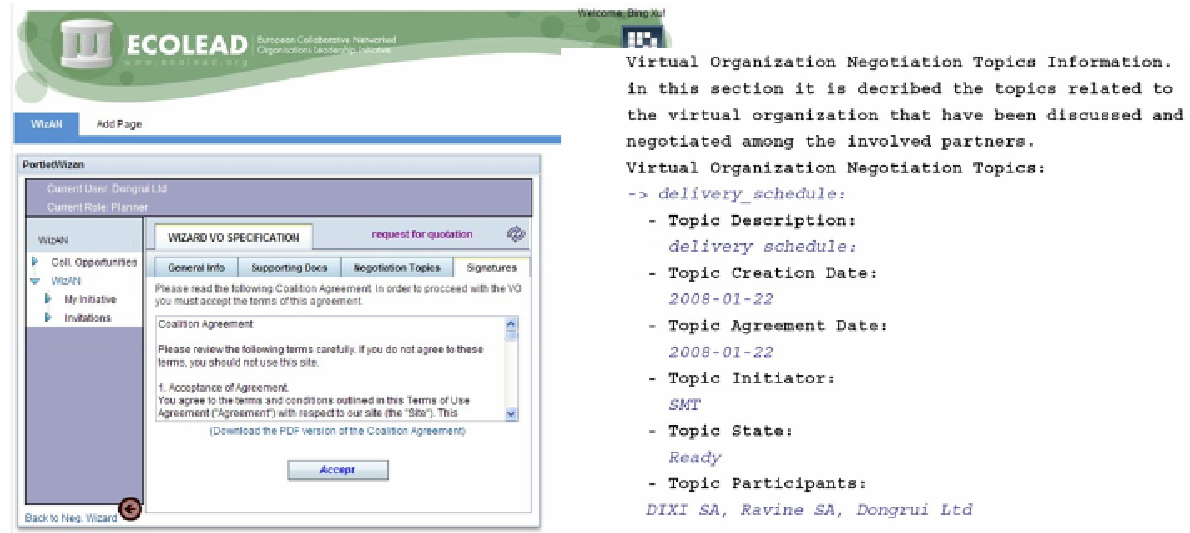

Figure 12 - WizAN user interface for agreement signing / example of agreement document 


\section{CONCLUSIONS}

The time and amount of resources consumed during the VO creation process whenever a business/collaboration opportunity is acquired, give a good indication of the level of agility of a collaborative network. The effectiveness of this process mainly depends on the availability of adequate information about potential partners and their level of preparedness for VO involvement. The existence of a VO breeding environment facilitates the fulfillment of these requirements as it provides common infrastructures to its members.

But even in the context of a VBE it is necessary to improve the negotiation processes that must take place during a VO consortium formation. The Agreement Negotiation wizard (WizAN) was designed to facilitate this process, reducing the required time. Moreover, documented and registered commitments of all partners involved in the different negotiation topics significantly decrease the risk of misunderstandings and consequent contestations. The WizAN tool also contributes to make the quotation process in a collaborative network compliant with the ISO 9000 certification that requires repeatable and traceable processes.

Acknowledgements. This work was funded in part by the European Commission through the ECOLEAD project.

\section{REFERENCES}

Angelov, S. (2006). Foundations of B2B Electronic Contracting. Unpublished PhD, Technische Universiteit Eindhoven, Eindhoven.

Camarinha-Matos, L. M., \& Afsarmanesh, H. (2003). Elements of a base VE infrastructure. J. Computers in Industry, Vol. 51(Issue 2), pp. 139-163.

Camarinha-Matos, L. M., Afsarmanesh, H., \& Ollus, M. (2005). Virtual Organizations: Systems and Practices. Boston: Springer.

Camarinha-Matos, L. M., \& Oliveira, A. I. (2006, 18-20 September). Contract Negotiation Wizard for VO Creation. Paper presented at the 3rd International CIRP Conference on Digital Enterprise Technology - DET'06, Setúbal.

Camarinha-Matos, L. M., Oliveira, A. I., Ratti, R., Baldo, F., \& Jarimo, T. (2007). A Computer-Assisted VO Creation Framework. Establishing the Foundation of Collaborative Networks, pp. 165178.

Rabelo, R. J., Camarinha-Matos, L. M., \& Vallejos, R. V. (2000). Agent-based Brokerage for Virtual Enterprise Creation in the Moulds Industry, E-business and Virtual Enterprises (pp. pp. 281290): Kluwer Academic Publishers.

Rocha, A. P., Cardoso, H. L., \& Oliveira, E. (2004). Contributions to an electronic Institution supporting Virtual Enterprises' life cycle. Paper presented at the Virtual Enterprise Integration: Technological and Organizational Perspectives.

Shelbourn, M., Hassan, T., \& Carter, C. (2005). Legal and Contractual Framework for the VO. In L. M. Camarinha-Matos \& H. Afsarmanesh \& M. Ollus (Eds.), Virtual Organization Systems and Practices: Springer. 